\title{
Skeletal Variation among Mesolithic People of the Ganga Plains: New Evidence of Habitual Activity and Adaptation to Climate
}

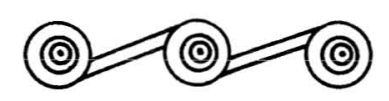

JOHN R. LUKACS AND J. N. PAL

The PREHISTORIC CUlTURAL PERIOD KNOWN AS MESOlithic initially referred to a hiatus in the record of human technological achievement, separating Paleolithic from Neolithic cultures in Europe. By the 1880s, as this cultural discontinuity was slowly filling with evidence of miniature stone tools, the term microlithic was proposed for this period of cultural decline following the Upper Paleolithic florescence in technology, painting, and sculpture (Kennedy 2000). Today, while some scholars question the utility of broad, culture-phase nomenclature, the label Mesolithic typically refers to cultures characterized by several key technological and adaptive characteristics, including: (1) miniature stone tools (microliths), (2) increased reliance on composite tools (sickles, bow and arrow), (3) increased subsistence diversity, including reliance on plants, fish, and birds, (4) larger and more sedentary settlements, and (5) enhanced regional variation and cultural diversification.

In India, Mesolithic cultures exhibit high regional diversity as one aspect of successful adaptations to such ecologically distinctive habitats as the arid zone of the Thar Desert, the humid tropics of Sri Lanka, and the high rainfall, wooded regions of eastern India. V. N. Misra (1996) notes that Mesolithic sites in India are larger, better preserved, and more numerous than their Paleolithic antecedents, in part because they are more recent in time, but also because Holocene geomorphic disturbances have been minimal. Knowledge of Mesolithic cultural adaptations in India is dramatically enhanced over preceding cultural phases by the presence-for the first time in Indian prehistory-of an abundant and informative series of human skeletal remains.

The functional analysis of artifacts (Petraglia et al. 1999), spatial interpretation of bone and stone scatters (Potts 1988), and taphonomic assessment of faunal remains (Erlandson and Moss 2001) provide valuable insights into the activities and life-ways of prehistoric people. However, when a site also yields the skeletal

John R. Lukacs is in the Department of Anthropology, University of Oregon, Eugene, and J. N. Pal is in the Department of Ancient History, Culture, and Archaeology, University of Allahabad, India. 
remains of its human occupants, an additional highly informative and unique source of data becomes available for reconstructing past life-ways. For example, demographic data on the age and sex structure of mortuary samples may be associated with population density, disease load, and level of hygiene (Storey 1992), physical attributes of individual specimens, such as stature and skeletal robusticity, may provide anatomical clues regarding growth rates, mobility, and adaptation to climatic extremes (Pearson 2000), and skeletal and dental evidence of disease provides insight into the prevalence of growth disruption, infectious disease, and oral health conditions (Hillson 2000, 2001; Roberts and Manchester 1995).

In keeping with the theme of this volume-rethinking South Asian archaeology - this contribution adopts an analytic paradigm known as bioarchaeology, and uses it to better understand the activities and adaptations of the Mesolithic inhabitants of North India. Bioarchaeology is the analysis of human skeletons from past populations within an interpretive framework that includes attention to both the cultural and the geophysical context of those remains. An abridged summary of bioarchaeological method and theory by Larsen includes a synthesis of primary research accomplishments of this dynamic approach to human osteology (Larsen 1997). Typically the focus of bioarchaeological research is wide ranging and may include analysis of mortuary sites (Gamble et al. 2001; Robb et al. 2001), gender differences in dietary patterns (Lukacs 1996), variation in health status across social groups (Walker and Hewlett 1990; Walker et al. 1998) or subsistence transitions (Lukacs and Walimbe 1998; Lukacs et al. 2001). This study examines variation in the marks that muscular attachments leave on bone (musculoskeletal stress markers), arthritic degeneration of articular surfaces of bone (osteoarthritis), the length of limb bones and their relative proportions to one another, and variation in stature reconstructed from long bone lengths. Detailed analysis of human skeletal variations permits a clearer understanding of how Mesolithic people biologically adapted to early and middle Holocene environments of the Ganga Plain. While the human remains from Damdama comprise the primary focus of this study, previously described skeletal series from the neighboring Mesolithic sites of Sarai Nahar Rai (Kennedy et al. 1986), Mahadaha (Kennedy et al. 1992), and Lekhahia (Lukacs and V. D. Misra 1997, 2002), serve as valuable comparative samples.

This contribution addresses several important questions about conditions of existence during the Mesolithic. How physically "stressful" were the daily lives of these people? Do skeletal variations among the people of Damdama reveal clues about the nature of repetitive or forceful activities? How tall were these foragers and how do they compare in stature with neighboring Mesolithic groups at Mahadaha and Sarai Nahar Rai? Can the limb proportions of these people be determined and interpreted in an adaptive evolutionary framework? Are their skeletons robust or gracile in structure and is evidence of biological adaptation to prevailing climate discernable? The answers to these questions will contribute new perspectives on the past and lead to a clearer picture of Mesolithic life-ways in North India. The rich and informative perspective of bioarchaeology cannot be derived from artifactual, taphonomic, or stratigraphic data alone, but must rely on biological evidence obtained directly from the human skeleton. Consequently, in this approach to the past, human skeletal observations serve as an indispensable and valuable complement to more traditional archaeological perspectives. 


\section{ARCHAEOLOGY AND CHRONOLOGY}

In 1972, the University of Allahabad began excavations at the Mesolithic site of Sarai Nahar Rai under the direction of G. R. Sharma (1973). Subsequently, two additional sites with human burials were discovered: Mahadaha, excavated in the late 1970s (Pal 1985, 1988; Sharma et al. 1980), and Damdama, excavated in the mid-1980s (Varma et al. 1985). All three sites are located between 40 and $80 \mathrm{~km}$ north of Allahabad (Fig. 1), preserve evidence of human occupation adjacent to oxbow lakes, and have produced the largest collection of Mesolithic human skeletons in Asia. Excavations document hearths and food refuse, microlithic and bone tools, fauna and flora, as well as abundant human burials with simple jewelry of bone and antler. Colloquium 33 of the 13th International Congress of Prehistoric and Protohistoric Sciences is devoted to the bioarchaeology of Mesolithic India (Afanas'ev et al. 1996), and includes new data on plant and animal resources at Damdama (Kajale 1996; Thomas et al. 1996), lithic use-wear analysis (Pal 1996), a review of burial practices (Pandey 1996), rock art evidence of subsistence practices (Varma 1996), as well as historical and synthetic perspectives (V. D. Misra 1996; V. N. Misra 1996). In addition, the skeletal adaptations of human remains from Mahadaha and Sarai Nahar Rai are compared (Kennedy 1996) and new AMS dates and carbon isotope values are reported for Damdama and Lekhahia (Lukacs et al. 1996).

Burials at Damdama are typically shallow oblong pits, in which the corpse was placed in an extended supine position, often oriented east-west. Position of the corpse is variable, with a range of flexion observed at the knee and elbow, and with some individuals buried in the prone position. Grave goods are rare and include simple jewelry, animal bones, and artifacts. Six multiple burials were excavated at Damdama, five double burials (Damdama 6, 16, 20, 30, and 36), and one triple burial (Damdama 18) (Pal 1985, 1988, 1992). An innovative perspective on Mesolithic mortuary practices in the Ganga Plain provides insights into issues regarding settlement pattern, social organization, and territoriality (Chattopadhyaya and Chattopadhyaya 1990).

The chronological placement of these sites is problematic. Some scholars are highly critical of the early Holocene date from Sarai Nahar Rai $(10,050 \pm 110$ B.P.), which was favored by G. R. Sharma (1973; Sharma and Sharma 1987). Charcoal is rare or absent, requiring the analysis of less traditional materials for dating purposes (bioapatite vs. collagen; shell vs. charcoal) consequently giving rise to questions of suitability, contamination, and methodology, which have resulted in a controversial chronological framework. Earlier radiocarbon dates are variable, with Sarai Nahar Rai and Mahadaha yielding some early and some late Holocene results (Possehl and Rissman 1992). Since 1992, several new ${ }^{14} \mathrm{C}$ dates have been published that suggest a mid-Holocene antiquity for Mahadaha (6320 \pm 80 B.P.; OxA-1647; Chattopadhyaya 1996) and a mid- to early Holocene age for Damdama (Lukacs et al. 1996). Two AMS dates derived from human bone samples from Stratum 1 (earliest) and Stratum 6 (middle) at Damdama have yielded dates of 8865 and $8640 \pm 65$ в.P., respectively (Lukacs et al. 1996). By contrast, three dates derived from bioapatite of bovid enamel are reported here for the first time and suggest a younger age, between $5550 \pm 60$ B.P. 


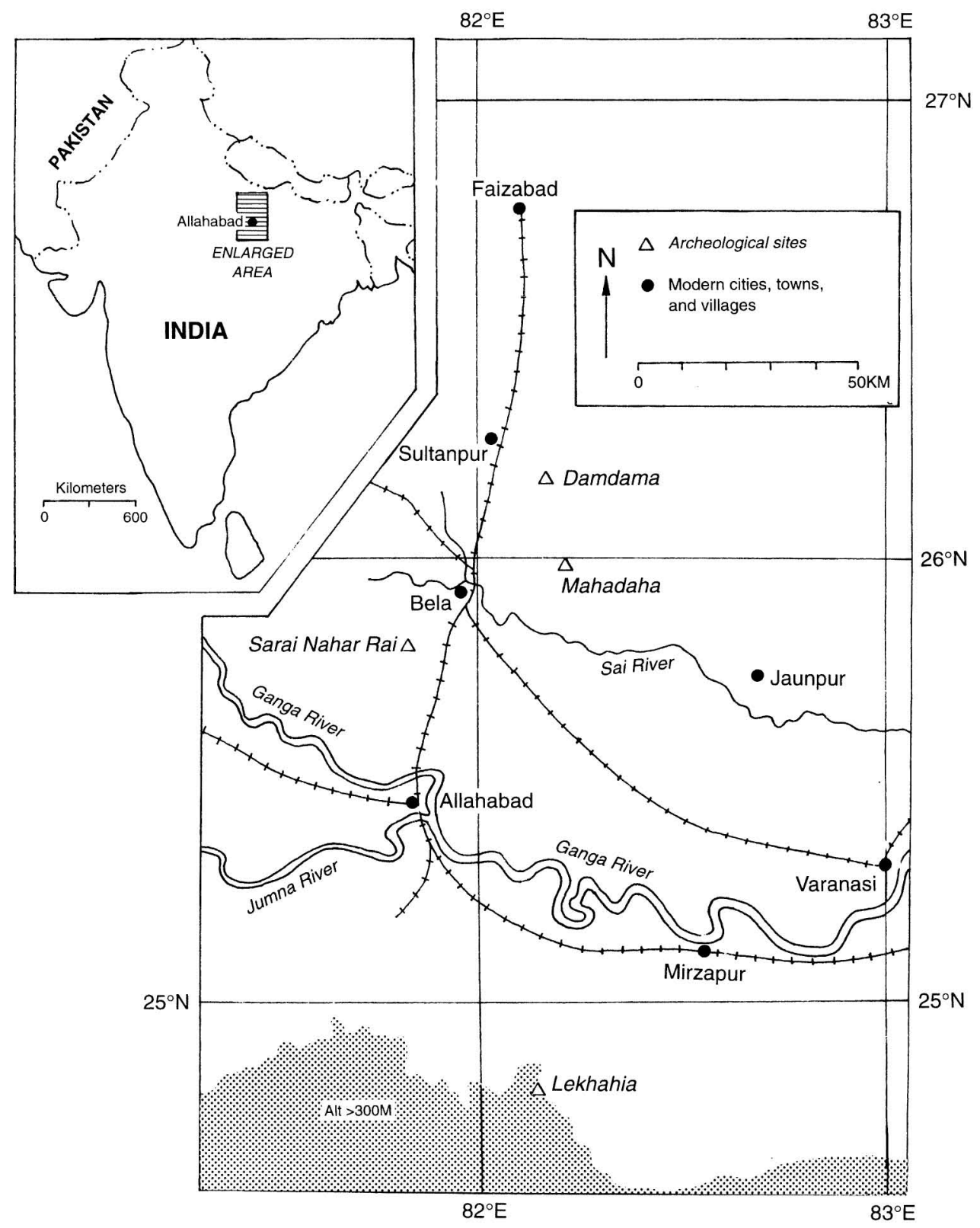

Fig. 1. Location map showing the physical setting of Mesolithic sites discussed in the text in relation to the Ganga-Jumna River confluence and the modern cities of Allahabad and Varanasi (Benares).

and $5250 \pm 70$ B.P. (Table 1). While enamel is less subject to postmortem diagenesis, the earlier dates are derived directly from the human skeletons. Resolution of this discrepancy in radiocarbon dates is currently underway by dating enamel samples from human remains, bone samples from bovids, as well as chemical characterization of the sedimentary matrix. 
Table i. AMS Radiocarbon Dates from Bovid Enamel (Bioapatite)

\begin{tabular}{|c|c|c|c|c|c|c|c|}
\hline SITE & $\begin{array}{c}\text { GEOCHRON ID } \\
\text { NUMBER } \\
\text { (SAMPLE \#) }\end{array}$ & STRATUM & SQUARE & $\begin{array}{c}\text { DATE } \\
\text { EXCAVATED }\end{array}$ & BONE \# & AGE (B.P.) & $\delta^{13} \mathrm{C} \%$ \\
\hline DDM & GX-22887-AMS (1) & 1 & S-15 & 1987 & 378 & $5550 \pm 60$ & 0.5 \\
\hline DDM & GX-22888-AMS (3) & 6 & $\mathrm{~N}-4$ & 1984 & - & $5250 \pm 70$ & 0.9 \\
\hline DDM & GX-22889-AMS (6) & 8 & $\mathrm{P}-10$ & 1984 & 126 & $5430 \pm 60$ & 1.0 \\
\hline
\end{tabular}

Note: Analysis conducted at Geochron Laboratories, Cambridge, MA; for AMS dates from human bone refer to Lukacs et al. 1996.

The remains of 47 adults are preserved at Damdama. This series is especially valuable because it (1) constitutes the largest group of Mesolithic skeletons from one site in South Asia, (2) comprises more than 50 percent of the North Indian skeletal sample, (3) permits the first statistical assessment of human biological adaptations for Mesolithic people of South Asia, and (4) yields new data that relate to several currently contentious theoretical issues in biological anthropology. This paper reports new data regarding the degree of musculoskeletal stress and extent of osteoarthritis in postcranial skeletons from Damdama, as well as variation in adult stature, and limb length and proportions. These data are used to infer habitual activity patterns and biological adaptations to the environment.

\section{RESEARCH CONTEXT: PREVIOUS BIOARCHAEOLOGY}

Bioarchaeological analyses of human remains from Lekhahia and Sarai Nahar Rai were initiated by Lukacs (1977). Subsequent comprehensive studies of series from Mahadaha and Sarai Nahar Rai in the 1980s, revealed a tall, large-framed people, who possessed large teeth and jaws, yet had few pathological lesions (Kennedy et al. 1986, 1992). The dental anthropology of Damdama was preliminarily described by Lukacs and Pal (1992, 1993). Large tooth size, low frequency of dental abscesses, low dental caries rates, low antemortem tooth loss, and high levels of dental attrition typify the people of Damdama, and are traits consistent with a coarse diet and a hunting and foraging subsistence base. In dental size, morphology, and pathology, the human remains from these three sites were found to present a homogeneous adaptive dental pattern (Lukacs and Pal 1992, 1993). Kennedy's prior analyses of skeletal variations in the Mahadaha and Sarai Nahar Rai series suggest a homogeneous morphological pattern in terms of stature, robusticity, and skeletal pathology (Kennedy et al. 1986, 1992). Reassessment of age at death at Damdama was conducted by Robbins (2000), who used variations in dental microstructure to resolve questions regarding palaeodemography. A more recent analysis of skeletal pathology at Damdama was conducted within the framework of subsistence transition theory (Lukacs and Pal 2003). This study found that indicators of iron deficiency (cribra orbitalia, porotic hyperostosis) and nonspecific systemic infection (periostitis) were absent from the Damdama skeletal series, findings consistent with a nomadic mobility pattern, low population density, and a hunting and foraging subsistence system. This result confirms prior insights regarding subsistence and diet derived from the dental 
pathology profile and tooth size variation reported at Damdama, and further affirms the similarity of the denizens of Damdama to their neighbors at Mahadaha and Sarai Nahar Rai.

\section{METHODS}

The level of mechanical loading of limbs in different types of activities and mobility patterns may directly impact the skeleton. Evidence of differential mechanical loads may be discerned in the size and rugosity of muscle attachment sites (entheses and musculoskeletal stress markers; Hawkey and Merbs 1995), pathological fractures and arthritic reactions (Lovell 1994), and in the crosssectional geometry of long bone diaphyses (Stock and Pfeiffer 2001). Successful osteological research on activity patterns of past people may focus on a single individual or small sample of specimens (Hawkey 1998; Lai and Lovell 1992), or alternatively, may involve skeletal series of moderate to large size that are approached from a statistical or population perspective (Hawkey and Merbs 1995; Robb 1998). All postcranial skeletal elements in the Damdama series were observed with the naked eye and under low magnification $(3 \times)$ for pathological lesions (Ortner and Putschar 1981) and peri- and postmortem modifications (White 1992).

The analysis of entheses or musculoskeletal stress markers in the skeletons from Damdama was conducted prior to the publication of standards for evaluating the relative degree of hypertrophy at specific sites. Two sets of standards are currently available that use discrete categories for classifying the size and severity of musculoskeletal stress markers. Hawkey and Merbs (1995) recommended a discrete fourfold classification $(0=$ absent, $1=$ faint, $2=$ moderate, $3=$ strong $)$ that they used to evaluate muscular origin and insertion rugosity, stress lesion size, and ossification exostosis. By contrast, Robb (1998) used a five-scale system to classify 18 muscle insertion sites in 56 skeletons from the Iron Age cemetery at Pontecagnano, Italy. Our description of variation in entheses at Damdama will refer to approximate equivalences in the Hawkey and Merbs (1995) methodology, as their system of classification provides more extensive photographic documentation of skeletal variation. All muscle and ligament attachment sites were examined with reference to their size, roughness, and prominence.

Supplemental guidelines for paleopathological analysis follow the procedures described by Aufderheide et al. (1998) and Lovell (1997, 2000), while recognition and scoring of degenerative joint disease, or osteoarthritis, follows protocols established by Jurmain (1999). Long bone measurement followed standardized procedures for maximal length as described by Haas et al. (1994) and Ubelaker (1989). Initially, only complete and well-preserved long bones were used in the estimation of stature. To enhance sample size, long bones that had one epiphysis preserved and were at least three-quarters complete and a few long bones with a slight degree of deformation were included in the analysis. Maximal length was estimated for long bones that were incomplete or warped. Estimation of living stature from maximal long bone length was calculated according to formulae derived from skeletal samples of American whites of European descent (Trotter 1970; Trotter and Gleser 1958) to facilitate comparison with stature data reported by Kennedy and associates $(1986,1992)$ for Mahadaha and Sarai Nahar Rai. 


\section{RESULTS}

Enthesial Hypertrophy, Osteoarthritis, and Activity Patterns

Entheses are sites throughout the skeleton where muscles attach to bone by tendon. In a structural-functional analytic paradigm, the extent and rugosity of entheses is approximately proportional to the size and activity of a muscle. In the skeletal sample from Damdama, enthesial hypertrophy was systematically evaluated as an indicator of skeletal function, activity level, and mobility, and as one factor contributing to the perception of "skeletal robusticity." Enthesial hypertrophy was observed at multiple loci throughout the skeleton and 57.6 percent $(19 / 33)$ of the specimens displayed enthesial hypertrophy at one or more sites. The distribution and frequency of enthesial hypertrophy by skeletal location is presented in Table 2, which shows upper and lower extremities equally affected. Affected sites are distributed across six locations in the upper limbs, with common loci of enthesial hypertrophy including the forearm, proximally near the elbow at the supinator crest and radial tuberosity, and distally at entheses of the pronator quadratus muscle. In the lower extremity, enthesial hypertrophy is clearly most prevalent and prominently developed at one site - the posterior proximal surface of the tibia, where the soleal line is developed into a rugose welt-like swelling (Hawkey and Merbs: grade 3). In more extreme instances this enthesis is hypertrophied into a ridge-like crest from which the soleus muscle originates (Hawkey and Merbs: grade 4). Hypertrophy of the soleal line is a marker of frequent and forceful plantar flexion and may be associated with high mobility, carrying heavy loads long distances, or locomotion in hilly terrain. Enthesial hypertrophy of the soleal line is equally well developed in the Damdama skeletal series among males and females and among adolescent and fully adult individuals of all ages.

A single instance of ossification exostosis was observed on the posterior surface of the right femur of specimen Damdama 23, an adult female. The exostosis is located $10 \mathrm{~cm}$ below the lesser trochanter and is on the lateral aspect of the linea aspera but contiguous with it. This area represents the proximal limit of the origin of the biceps femoris muscle. The "bone spur" is chevron shaped with the apex pointing proximally, the arms diverging distally, and a vascular cortical impression trailing from the disto-lateral aspect of the exostosis in a disto-lateral direction. In areal extent $(3 \mathrm{~cm}$ long) and degree of projection from the cortical surface $(>10 \mathrm{~mm})$, this exostosis is classified as a strong expression $(\mathrm{OS}=3)$ of the trait (Hawkey and Merbs 1995). Ossification exostoses are usually due to abrupt macrotrauma such as muscle rupture. This particular exostosis represents a serious injury to the short head of the biceps femoris muscle (the lateral member of the hamstring group), probably caused by a unique, extreme action, such as hyperextension at the knee joint.

Levels of mobility within and between groups may also be approached through the analysis of postcranial osteoarthritis. Theory and issues relevant to this research strategy are reviewed by Hemphill (1999), who adopts a bioarchaeological approach to osteoarthritis in evaluating levels of mobility among Great Basin hunter-gatherers. Three types of bone modification were recorded as evidence of osteoarthritis: eburnation, porosity, and proliferative bone growth (osteophytes) at joint margins (Jurmain 1999). Sample size in this analysis fluctuates from joint to joint, and not all articular surfaces could be observed at each 
Table 2. Distribution and Relative Frequency of Enthesial Hypertrophy at Damdama

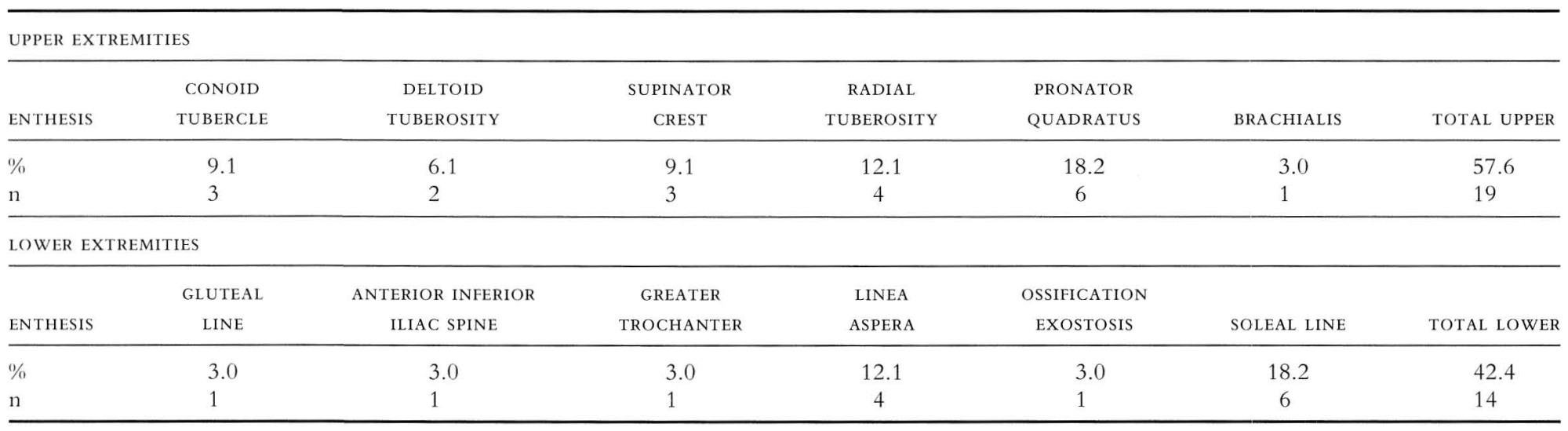

$\%=$ frequency of hypertrophic development at a specific site in comparison with other sites of musculoskeletal stress markers or enthesis hypertrophy.

$\mathrm{n}=$ number of instances in which a specific site (musculoskeletal stress markers or enthesis) exhibited hypertrophic development (grade 3 or 4 of Hawkey and Merbs 1995). 
Table 3. Loci and Relative Frequency of Osteoarthritis at Damdama

\begin{tabular}{|c|c|c|c|c|c|c|c|c|}
\hline \multirow[t]{3}{*}{ UPPER LIMBS } & \multicolumn{2}{|c|}{ SHOULDER } & \multicolumn{2}{|c|}{ ELBOW } & \multicolumn{2}{|c|}{ WRIST } & \multicolumn{2}{|c|}{ HAND } \\
\hline & $\%$ & n & $\%$ & n & $\%$ & $\mathrm{n}$ & $\%$ & $\mathrm{n}$ \\
\hline & 0.0 & 18 & 4.5 & 22 & 0.0 & 11 & 10.0 & 10 \\
\hline \multirow[t]{3}{*}{ LOWER LIMBS } & \multicolumn{2}{|c|}{ HIP } & \multicolumn{2}{|c|}{ KNEE } & \multicolumn{2}{|c|}{ ANKLE } & \multicolumn{2}{|c|}{ FOOT } \\
\hline & $\%$ & $\mathrm{n}$ & $\%$ & $\mathrm{n}$ & $\%$ & $\mathrm{n}$ & $\%$ & $\mathrm{n}$ \\
\hline & 0.0 & 16 & 0.0 & 17 & 0.0 & 13 & 0.0 & 13 \\
\hline
\end{tabular}

$\%=$ percentage of observed joints afflicted with osteoarthritis (includes marginal osteophytes, eburnation, and porosity).

$\mathrm{n}=$ number of joints observed (one or more of the articular surfaces at the joint were preserved for study).

joint, due to post-burial diagenetic and taphonomic factors influencing the differential preservation of skeletal parts. The age structure of the skeletal sample, on which osteoarthritis was assessed, ranges from 16 to 52 years with, a sex-pooled mean of 33.3 years. No significant difference exists between sexes in mean age at death. At Damdama, evidence of osteoarthritis was present, but rare. Vertebrae were poorly preserved and underrepresented in the sample; however, vertebral osteophytes were observed in three specimens (Damdama 1,8,12) of seven with preserved vertebrae (absent in Damdama 18a, 20b, 36a, 36b). Osteoarthritis of the appendicular skeleton is low in frequency and was observed bilaterally in the elbows of one individual (Damdama 1, female) and in the hand of another (metacarpals, Damdama 12, female). The low incidence of osteoarthritis in the appendicular skeleton suggests that predisposing factors such as repetitive forceful use of the limbs and traumatic injury were also rare (Table 3). By contrast, involvement of the axial skeleton appears more common, and may indicate frequent bearing of heavy loads-an observation consistent with hypertrophy of the soleal line. Osteoarthritis of the temporomandibular joint is rare at Damdama and is related to the biomechanics of mastication not mobility and, consequently, will be discussed in more detail elsewhere (Lukacs and Pal 2003).

\section{Stature at Damdama: A Comparative Assessment}

Descriptive statistics were computed for all postcranial osteometric variables for all traditionally recorded dimensions. In Table 4, we present mean maximum length of long bones of the Damdama skeletal series by sex. The data on which these summary statistics were computed constitute the basis for the analysis of upper and lower limb segment proportions and the estimation of stature. Maximum long bone length was entered into regression formulae for white Europeans to estimate stature (Trotter 1970). Estimations of living stature could be calculated for 29 specimens from Damdama, yielding mean ( \pm 1 standard deviation) values of $179.1 \mathrm{~cm}( \pm 8.1 \mathrm{~cm})$ for 18 males and $173.0 \mathrm{~cm}( \pm 10.1 \mathrm{~cm})$ for 11 females. These values are graphically compared with mean stature estimates for Mahadaha, Sarai Nahar Rai (Ganga Plain sites), and for Lekhahia (located in the Kai- 
Table 4. Mean Long Bone Length by Sex (in mm)

\begin{tabular}{|c|c|c|c|c|c|}
\hline ELEMENT & $\mathrm{N}$ & MEAN & SD & MIN & $\operatorname{MAX}$ \\
\hline \multicolumn{6}{|c|}{ MALE } \\
\hline Clavicle & 5 & 152.8 & 6.3 & 145.0 & 158.0 \\
\hline Humerus & 7 & 352.4 & 18.3 & 315.0 & 370.0 \\
\hline Radius & 6 & 276.7 & 26.2 & 254.0 & 325.0 \\
\hline Ulna & 5 & 293.0 & 22.3 & 268.0 & 322.0 \\
\hline Femur & 10 & 503.8 & 23.0 & 454.0 & 537.0 \\
\hline Tibia & 6 & 428.7 & 10.7 & 417.0 & 447.0 \\
\hline Fibula & 5 & 389.0 & 27.3 & 368.0 & 425.0 \\
\hline \multicolumn{6}{|c|}{ FEMALE } \\
\hline Clavicle & 2 & 134.0 & 12.7 & 125.0 & 143.0 \\
\hline Humerus & 4 & 339.0 & 26.1 & 309.0 & 370.0 \\
\hline Radius & 3 & 275.0 & 23.5 & 248.0 & 291.0 \\
\hline Ulna & 4 & 284.5 & 22.2 & 262.0 & 309.0 \\
\hline Femur & 3 & 469.3 & 18.9 & 453.0 & 490.0 \\
\hline Tibia & 3 & 388.3 & 29.7 & 363.0 & 421.0 \\
\hline Fibula & 4 & 385.8 & 29.0 & 353.0 & 417.0 \\
\hline
\end{tabular}

mur Hills) in Figure 2, and reveal greater intersite consistency for males than for females. The level of sexual dimorphism at Mahadaha $(6.5$ percent, $n=17$; male $181.1 \pm 5.6 \mathrm{~cm}, \mathrm{n}=13$; female $169.3 \pm 4.8 \mathrm{~cm}, \mathrm{n}=4$; Lukacs and Pal 1993) and at Chalcolithic Mehrgarh (8 percent, $\mathrm{n}=20$; male $171.1 \pm 7.1 \mathrm{~cm}$, $\mathrm{n}=6$; female $159.0 \pm 4.7 \mathrm{~cm}, \mathrm{n}=14$; Lukacs and Hemphill 1991) is greater than at Damdama for which sexual dimorphism is 3.4 percent [percent sexual dimorphism $=(M-F / M) \times 100]$.

The Damdama and Mahadaha series are used to place Indian Mesolithic stature in broader comparative context, because larger samples are available from these sites and because the two females from Sarai Nahar Rai yielded a suspiciously tall mean stature $(188.9 \pm 1.6 \mathrm{~cm}$; calculated from data presented in Kennedy et al. 1986:71, Table 6; using stature estimates from bone lengths and formulae with the lowest standard error). Mean stature for both Damdama and Mahadaha is significantly taller than European Mesolithic skeletal samples. Recently published stature data for Mesolithic Europe reveals a clinal pattern from Western European sites with short stature, to Eastern groups with intermediate stature (Formicola and Giannecchini 1999). Figure 3 shows that individuals from both Damdama and Mahadaha are significantly taller than Mesolithic Europeans. In Formicola's opinion, the observation that Upper Palaeolithic skeletal series are taller than Mesolithic series in Europe may have several plausible explanations: (1) better nutrition; (2) retention of ancestral heat-adapted limb proportions; (3) outbreeding mating patterns led to genetic heterozygosity; and (4) natural selection optimized stride length and locomotor efficiency. Collectively, these factors may also have played a role in selecting for tall stature among North Indian Mesolithic groups, which display greater similarity in stature to Upper Paleolithic than to Mesolithic Europeans. 


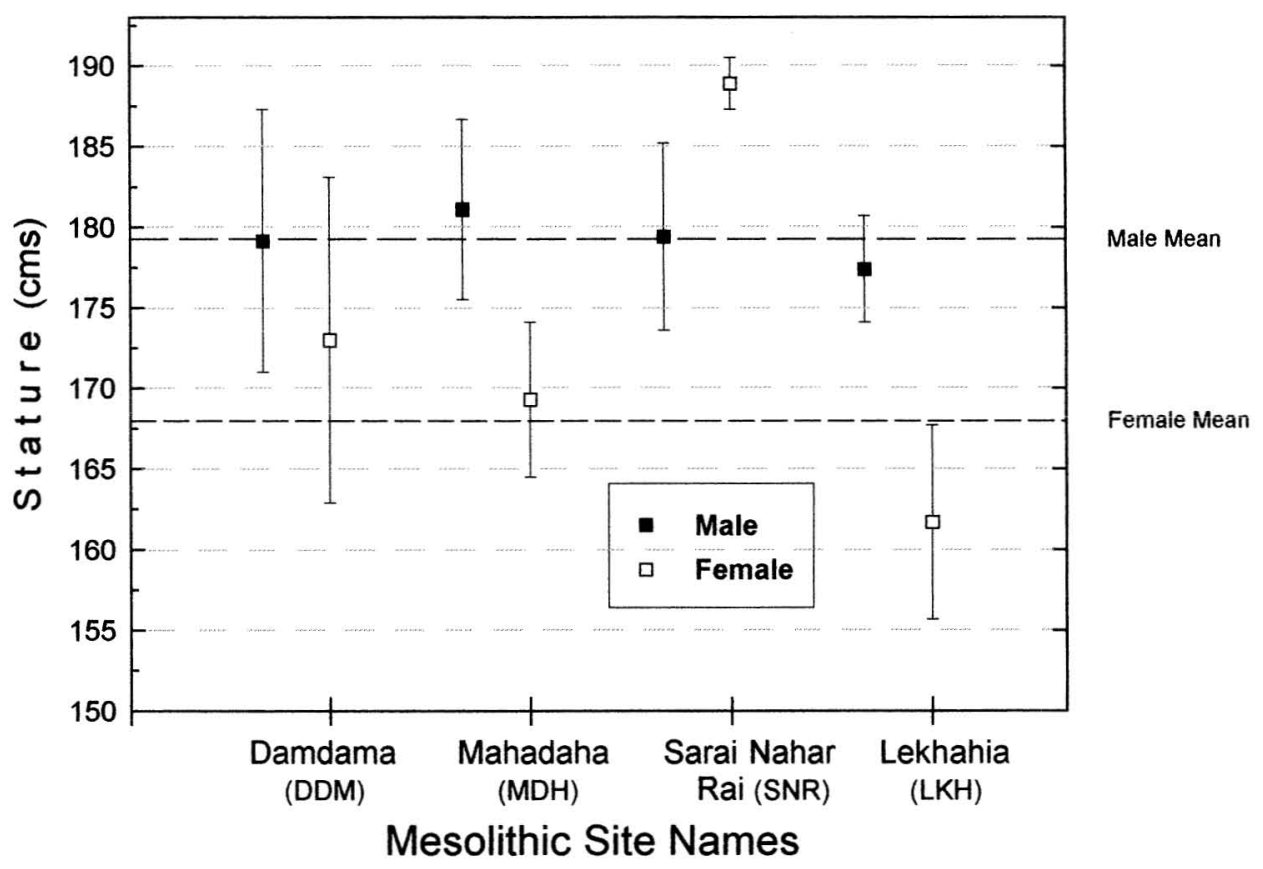

Fig. 2. Mean stature for Mesolithic Indian skeletal series: Ganga Plains (DDM, MDH, SNR) and Vindhya Hills (LKH) (error bars $= \pm 1$ standard deviation). Data for MDH and SNR from Kennedy et al. (1986, 1992), for LKH from Lukacs and Misra (1997) and for DDM revised from Lukacs and Pal (1993: 761, Table 14).

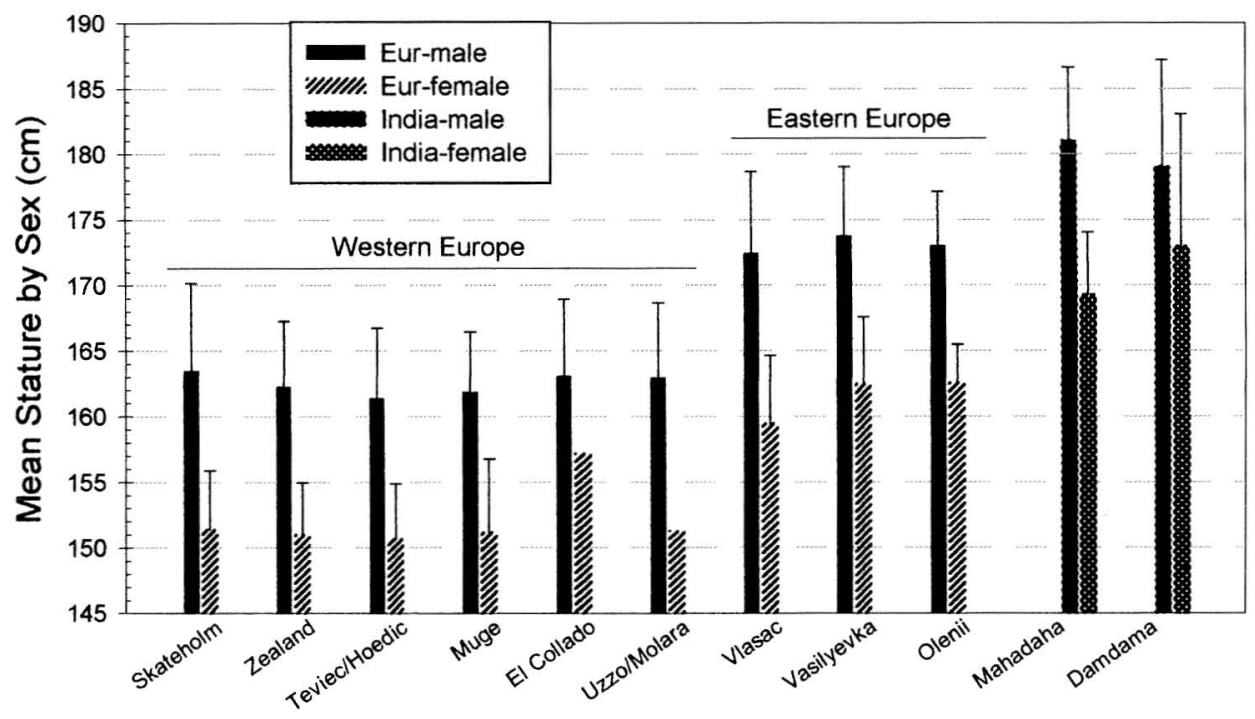

Fig. 3. Mesolithic variation in stature: Europe and North India compared (error bars $= \pm 1$ standard deviation). European data from Formicola and Giannecchini (1999:324, Table 4a). 


\section{Limb Length, Skeletal Robusticity, and Climatic Adaptation}

With the exception of their utility in estimating stature of the deceased, data derived from postcranial osteometry have long been viewed as esoteric minutiae relegated to the appendices of anthropological and archaeological reports. Today, analysis of the postcranial skeleton has taken center stage in bioarchaeological research and currently involves biomechanical analysis of stress on the skeleton (Ruff 2000) and utilizes a blend of traditional osteometry and innovative techniques, such as CT scans and digital image analysis (Bridges 1989), which yield new perspectives on activity patterns and climatic stresses in prehistory (Ruff 1999).

A bivariate scatterplot of lower limb lengths for individual specimens from Damdama is presented in Figure 4. For comparison, the mean limb length values of populations residing in warm and cold climates are included in the plot (data from Trinkaus 1981). The regression lines are clearly distinct, with warm climate groups having longer tibias for a given femur length than groups from cold climes (see Fig. 4 caption for group names). The specimens from Damdama fall nearest the regression line for warm climate groups, who have relatively long limbs overall and especially long tibias. This pattern of distal limb segment elongation also characterizes the upper extremities of the Damdama skeletal series and illustrates a pattern of variability consistent with the ecogeographic rules of Allen (1877) and Bergmann (1874). Long limbs and linear body builds are selected for in hot arid

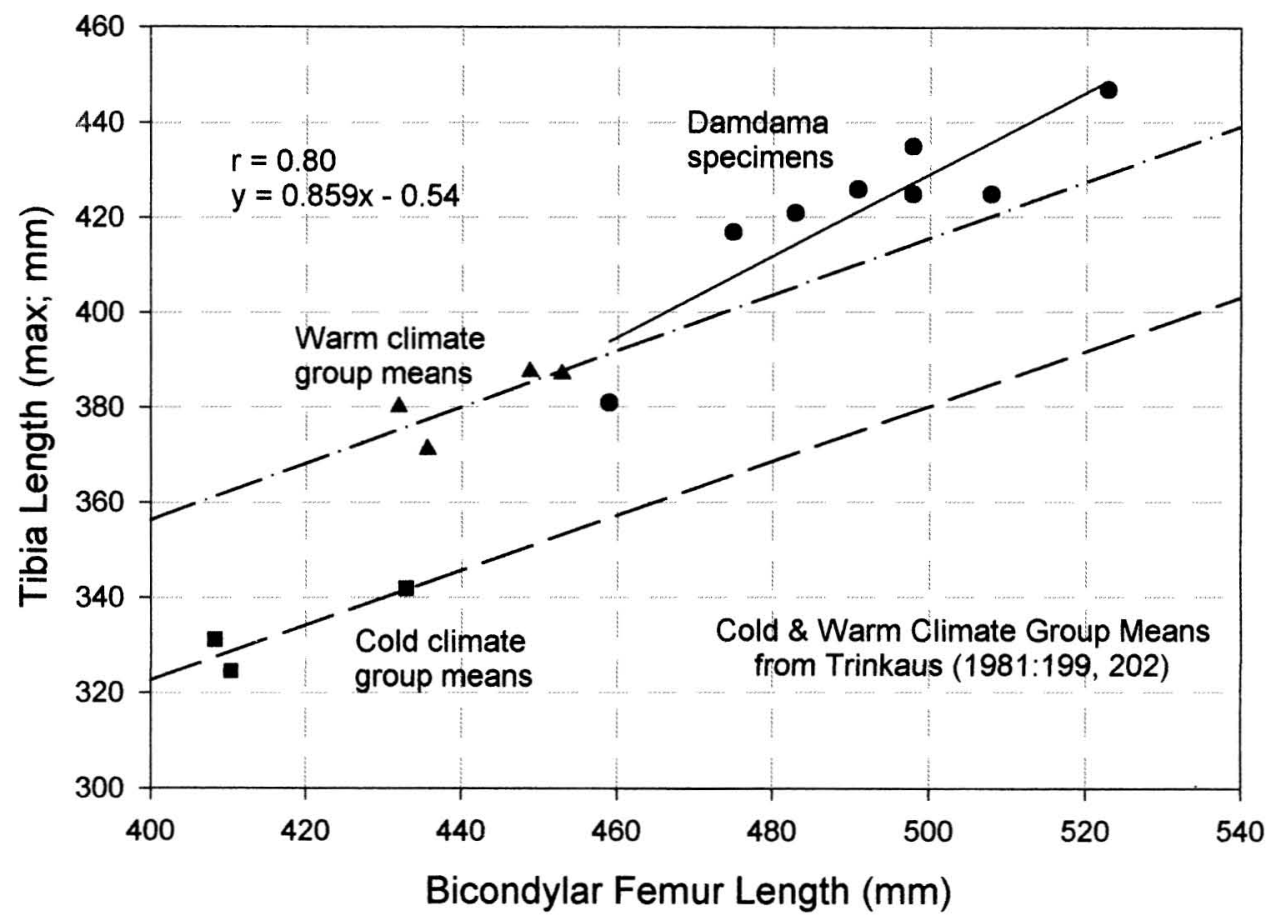

Fig. 4. Lower limb proportion scatterplot: tibia vs. femur. Circles = values for individual specimens from Damdama (DDM-12, 16a, 16b, 23, 24, 25, 36a, 36b); triangles = warm climate group means (Bantu, Egyptian, Melanesian) and the individual Kenyan fossil, Homo crgaster (WT 15,000; Walker and Leakey 1993); squares = cold climate group means (Eskimo, Lapplander, Neandertal). Data source: Trinkaus 1981:199, Table 3; 202, Table 5). 
regions because they facilitate physiological thermoregulation through heat dissipation. When compared with Holliday's (1999) data on Mesolithic European limb length, and upper (brachial) and lower (crural) limb indices, the Damdama skeletons exhibit significantly longer limbs.

The analysis of postcranial robusticity has recently been used to resolve anthropological problems of general interest to archaeologists and bioanthropologists, such as the likelihood of continuity vs. replacement in the origin of modern humans in Europe, and changes in the level of physical stress across the subsistence transition from foraging to farming in the Southeast United States. Results of robusticity studies have provided both surprises and insights, as illustrated below. Here we raise the contentious question, "Do the Mesolithic inhabitants of Damdama exhibit robusticity in the morphological structure of their postcranial skeleton?" Skeletal robusticity in the Damdama skeletal series is evaluated using two standard measures of robusticity traditionally employed in human osteology: the diaphyseal robusticity index and epiphyseal robusticity index. The diaphyseal robusticity index relates a measure of bone shaft size (circumference, transverse, or anterior-posterior diameter) to a measure of bone length (maximal, physiological, or articular). The epiphyseal (or articular) robusticity index relates a measure of articular or epiphysis size (head diameter, biepicondylar, or bicondylar width) to a measure of bone length (see Pearson 2000, for bone and index-specific formulae). Though different investigators employ a variety of different formulae in computing indices of robusticity, we have selected two recent studies for the purpose of contextualizing the level of robusticity at Damdama (Collier 1989; Pearson 2000).

In the first analysis, Pearson's (2000) diaphyseal robusticity index is plotted on the horizontal axis and the epiphyseal robusticity index is graphed on the vertical

Table 5. Robusticity Index: Femur

\begin{tabular}{|c|c|c|c|c|c|c|c|}
\hline \multirow[b]{2}{*}{ SPECIMEN } & \multirow[b]{2}{*}{ SEX } & \multicolumn{3}{|c|}{ DIAPHYSEAL } & \multicolumn{3}{|c|}{ EPIPHYSEAL (DISTAL) } \\
\hline & & $\mathrm{AP}+\mathrm{ML}$ & $\begin{array}{c}\text { BICONDYLAR } \\
\text { LENGTH }\end{array}$ & INDEX & $\begin{array}{c}\text { BICONDYLAR } \\
\text { WIDTH }\end{array}$ & $\begin{array}{l}\text { MAXIMUM } \\
\text { LENGTH }\end{array}$ & INDEX \\
\hline 12 & $\mathrm{~F}$ & 52 & 459 & 11.3 & 68 & 465 & 14.6 \\
\hline $16 a$ & $M$ & - & - & - & 75 & 530 & 14.2 \\
\hline $16 \mathrm{~b}$ & M & - & - & - & 76 & 498 & 15.3 \\
\hline $20 \mathrm{~b}$ & M & 66 & 497 & 13.3 & - & - & - \\
\hline 21 & M & 54 & 448 & 12.1 & - & - & - \\
\hline $36 a$ & $\mathrm{~F}$ & 54 & 483 & 11.2 & 68 & 493 & 13.8 \\
\hline \multirow[t]{2}{*}{$36 b$} & M & 50 & 475 & 10.5 & 69 & 486 & 14.2 \\
\hline & & $\mathrm{n}$ & - & sd & $\mathrm{n}$ & - & sd \\
\hline Mean & $\mathrm{F}$ & 2 & 11.3 & 0.07 & 2 & 14.2 & 0.57 \\
\hline Mean & M & 3 & 12.0 & 1.40 & 3 & 14.6 & 0.64 \\
\hline \multirow[t]{5}{*}{ Total } & $\mathrm{F} \& \mathrm{M}$ & 5 & 11.7 & 1.07 & 5 & 14.4 & 0.57 \\
\hline & & & \multicolumn{5}{|c|}{ EPIPHYSEAL (PROXIMAL) } \\
\hline & & & SPEC. NO & SEX & HEAD & MAX LN & INDEX \\
\hline & & & 12 & F & 43 & 465 & 9.2 \\
\hline & & & 23 & $M$ & 48 & 505 & 9.5 \\
\hline
\end{tabular}




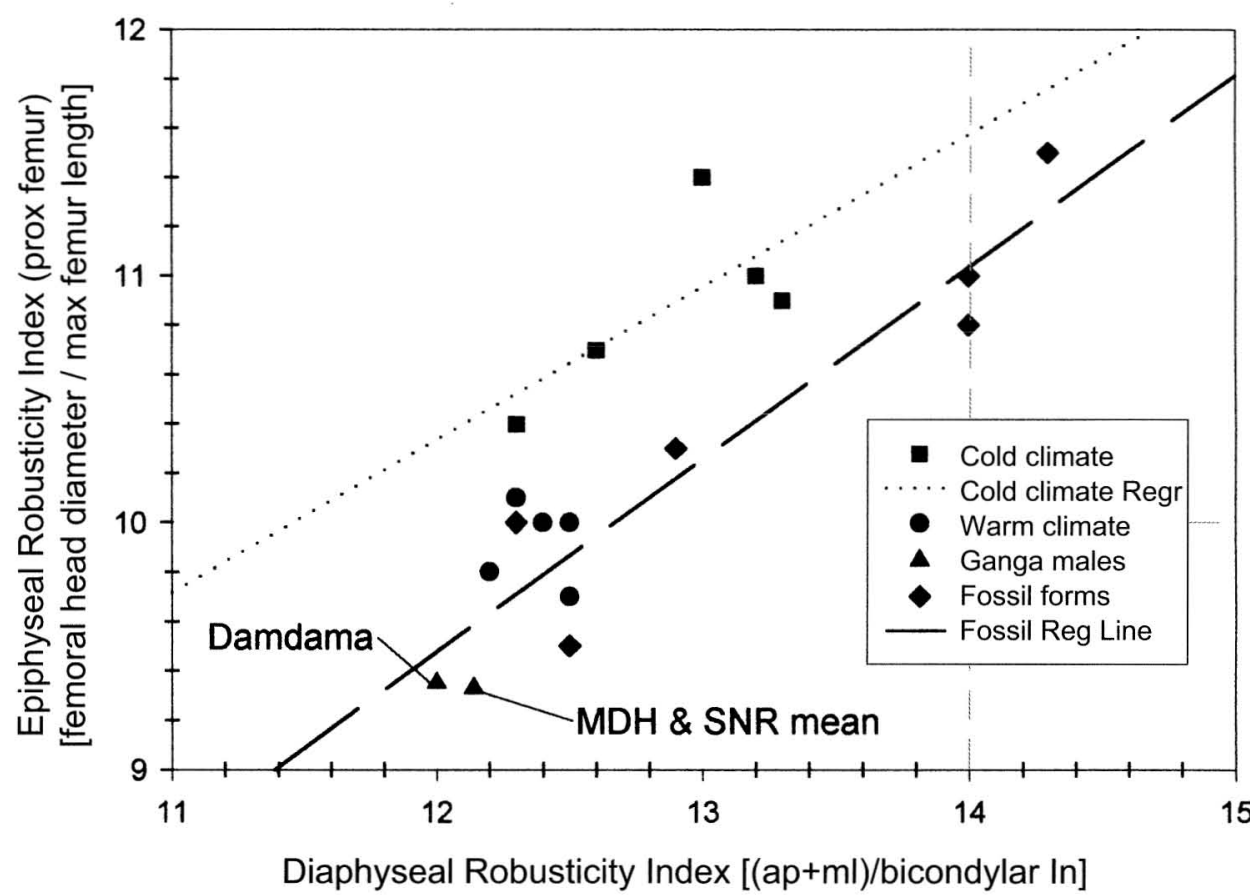

Fig. 5. Diaphyseal and epiphyseal robusticity: Damdama and Ganga Plains male femora in comparative context. This graph is a revised version of Pearson's Fig. 4b (2000:586), with DDM and Ganga male samples added. Data and sample names of individual cold and warm climate groups, and fossil forms, taken from Pearson (2000:578-579, Table 4; 580-581, Table 5) Ganga males (MDH and SNR; from Kennedy et al. 1986, 1992). (Figure redrawn from Pearson [2000; Fig. 4b, p. 586], with DDM and Ganga males and regression lines added.)

axis (Fig. 5). Squares and the dotted line represent cold climate groups, while circles represent samples from warm climates (data and sample names in Pearson 2000). Diamonds and the dashed line represent late Pleistocene and Upper Palaeolithic fossil samples. Note that triangles, representing males from Damdama and from Mahadaha and Sarai Nahar Rai (pooled mean) have the lowest values for both diaphyseal and epiphyseal robusticity. In these measures of robusticity the North Indian Mesolithic samples are gracile rather than robust, and cluster with groups that occupy warm environments.

In an effort to clarify disagreements regarding the robusticity of Australian aboriginal skeletons, in contrast to European immigrants, Collier (1989) analyzed five comparative samples in terms of multiple measures of robusticity: two urban groups (Terry Collection, Romano-Britons), and three hunter-gatherer groups (two Eskimo: southwest Alaska riverine and northern Alaska coast whalers; and one Native North American, Arikara). Surprisingly, Collier found that in all measures of robusticity, rather than being more robust as expected, aboriginal Australians were far more gracile than all comparative samples, even the urban groups. In both articular (epiphyseal, y-axis) and diaphyseal (x-axis) indices of femoral robusticity, aboriginal Australians are similar to the Mesolithic group from Mahadaha, and while Damdama and Sarai Nahar Rai are near the mid-range 


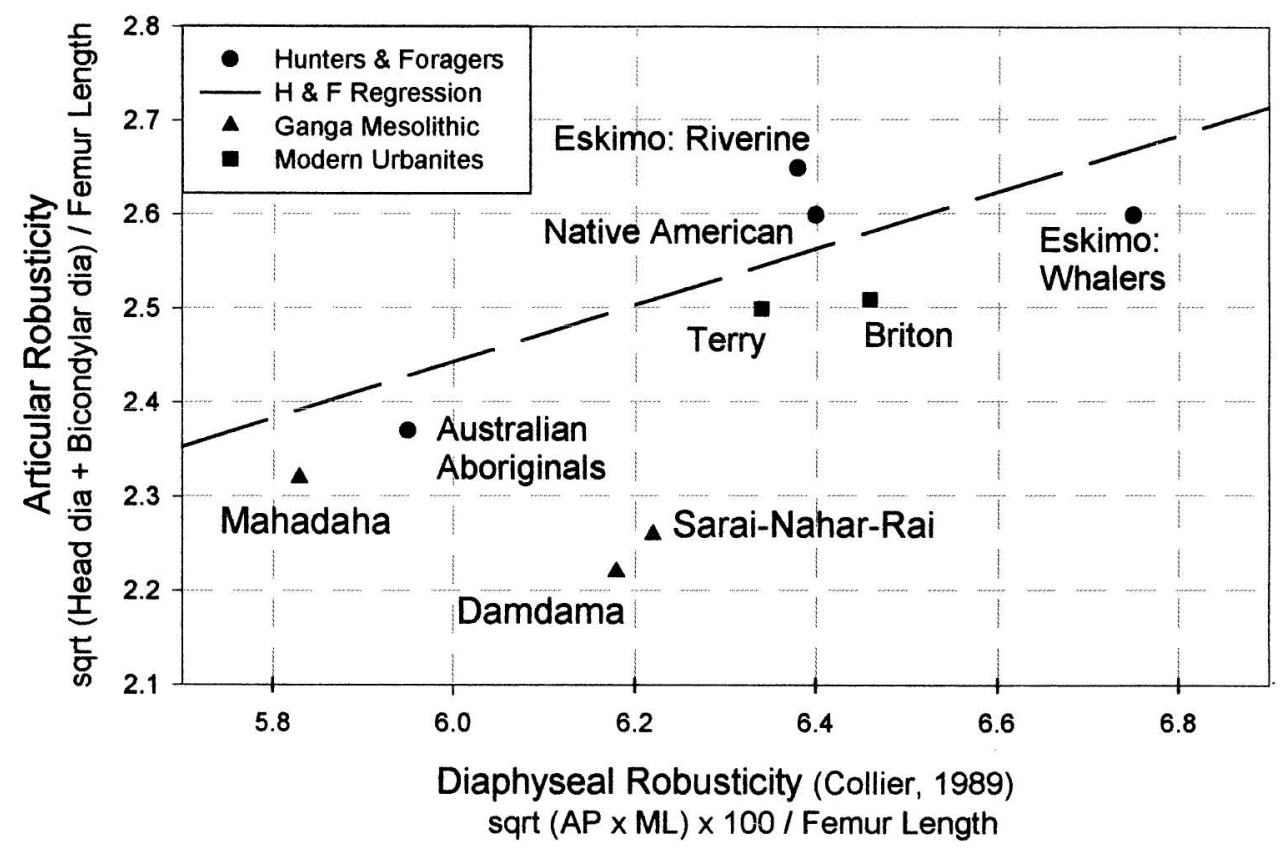

Fig. 6. Male femur robusticity: Mesolithic India in comparative context. For details on comparative groups: refer to Collier (1989) for modern urbanites (squares; Terry collection and modern Britons); and hunter-forager groups (circles; riverine and whaler Eskimo samples, a Native American series, and Australian Aboriginals); and to Kennedy and colleagues for SNR (1986) and MDH (1992) data.

of values for diaphyseal robusticity (horizontal axis), they have the lowest values for articular (epiphyseal) robusticity (vertical axis) (Fig. 6).

In sum, Pearson (2000) found diaphyseal and epiphyseal robusticity high among people inhabiting cold climates, and low among people inhabiting warm regions. The Mesolithic samples from North India cluster in this analysis with the denizens of warm climates. To Collier's surprise, Australian aboriginals were much less robust in limb indices than expected, possibly due to physiological adaptation to heat stress, but he proposed that low-stress subsistence activities may also be involved. The low robusticity of North India's Mesolithic foragers may be due to their tall stature and long upper and lower extremities, variations that represent biological responses to a warm climate. Elongation of lower limbs among the Indian Mesolithic skeletal series may result from the combined selective influence of heat stress and an adaptive response favoring locomotor efficiency among mobile foragers Further study of the biomechanics of limb structure in these study groups using cross-sectional geometric analysis may add to our knowledge of their postcranial skeletal adaptations.

\section{DISCUSSION}

Musculoskeletal Stress Markers, Enthesial Hypertrophy, and Activity Patterns

Insight into activity patterns at Damdama are modest, yet informative. They are modest in contrast with population-level studies of larger series and with the 
analysis of unique occupations or activities in smaller series or individual skeletons. For example, the analysis of musculoskeletal stress markers in a large skeletal sample of Hudson Bay Eskimo allowed Hawkey and Merbs (1995) to discern gender-specific activity patterns and to support a theory of substantial change in subsistence through time with osteological data. Alternatively, Molleson and colleagues distinguished a suite of skeletal markers associated with the habitual and strenuous activity of equid riding, from a distinct pattern of markers that result from routine cart or chariot riding. This permitted the identification of a cart driver from the Royal Cemetery in the Predynastic period at Ur (c. 25002350 B.C.; Molleson and Hodgson 1993), and four femora of probable bare-back equestrians at Kish (Molleson and Blondiaux 1994). One of the probable equestrians at Kish is significant because it derives from the first or second quarter of the third millennium $(2750$ в.c. \pm 100$)$ and thus antedates textual and archaeological documentation of horse riding (Molleson and Blondiaux 1994:314).

Though no highly distinctive or occupation-specific activities have been identified at Damdama, two informative patterns of musculoskeletal stress markers have been identified: (1) overhand throwing, and (2) long-distance or load-bearing locomotion. The throwing complex, may be associated with the forceful launching of spears or hurling of individual projectiles or bolas, activities envisioned as habitual among hunters, yet not without modern parallels (baseball pitching or cricket bowling, Kennedy 1983). This complex of musculoskeletal stress markers includes hyper-development of the anconeus and supinator muscles, and has been previously reported in the Mahadaha (Kennedy et al. 1992) and Sarai Nahar Rai (Kennedy et al. 1986) skeletal series. The recognition at Damdama of hypertrophy of proximal and distal forearm muscle sites (radial tuberosity, pronator quadratus attachments, sharp interosseous crests) reaffirm that activities involving the brachial complex favored the right side and were an important component of the Damdama activity pattern. Archaeological evidence from Damdama includes clay balls that could have served as projectiles or bolas, and stone points that were undoubtedly hafted to spear shafts. These artifacts are consistent with the activity patterns reconstructed from the analysis of entheses and musculoskeletal stress markers data from human skeletons at the site.

In the lower extremity, the high level of development of the soleal lineorigin of the soleus muscle-and related markers of the ankle and foot, such as the calcaneal tuberosity, suggest forceful and habitual plantar-flexion of the foot. The action implicated here is the propulsive "toe-off" segment of the bipedal stride, or an exercise known as "toe-raises" in which soleus and gastrocnemius muscles flex to raise the body and heel of the foot from the ground, displacing body weight to the ball of the foot and the toes. The highly developed markers of plantar flexion of the foot in the Damdama series are interpreted to represent a range of possible locomotor stresses, including walking long distances, carrying heavy loads while walking, or walking up steep grades. These are clearly not mutually exclusive activities and some individuals may have engaged to varying degrees in all three actions. Nevertheless, a differential diagnosis of relative degree of each activity from musculoskeletal stress markers size and severity in an individual skeleton is not possible. While extensive walking is clearly indicated from this analysis, distinguishing the osteological signature of locomotion in hilly terrain from walking long distance on level plains or differentiating osteological indicators of locomotion while carrying heavy loads (residential mobility) from 
walking shorter distances with lighter loads (logistical mobility), may require more refined quantitative analysis of cross-sectional geometry of bones of the lower extremity (Ruff 2000). Only with additional data, relating geometric variation in bone shape to the stress and strain of mechanical loads can the competing hypotheses of Mesolithic subsistence advanced by Sharma (1973) and Varma (1981-1983) be tested with human skeletal evidence (Lukacs 2002).

The musculoskeletal stress marker complexes identified at Damdama, in both upper and lower extremities, are not exclusively specific to one sex. Although the throwing complex tends to be more frequent or more highly developed in males, it occurs in both male and female specimens. The locomotor musculoskeletal stress marker complex is expressed to a similar degree in both sexes and in all ages from late adolescence to mature adult.

\section{Variation in Stature and Limb Proportions: Multiple Selective Agents}

The comparative analysis of postcranial skeletal variation among Mesolithic skeletal series from North India demonstrates that inhabitants of Damdama, Mahadaha, and Sarai Nahar Rai share a phenotypic pattern of body size and proportions that includes: (1) tall stature, (2) elongation of upper and lower limbs overall, and (3) lengthy distal limb segments (forearm and leg) relative to proximal limb segments (upper arm and thigh). This gracile and linear phenotype was revealed by plotting lower limb segment lengths (tibia vs. femur) and by plotting indices of femoral robusticity for Ganga Plains skeletal series against a range of skeletal samples from different climatic settings that practiced different subsistence and activity patterns. The Indian Mesolithic skeletal series consistently grouped with other samples from warm climates. Tall stature, long limbs, and relatively long distal limb segments are collectively regarded as a suite of traits that increase body surface area and thereby promote evaporative cooling as an adaptation to heat stress. The elongation of long bones results in a relative reduction of transverse measures of diaphyseal and epiphyseal (articular) width, presenting a linear and gracile skeletal pattern.

Other factors synergistically intertwine during growth and development to influence body size and shape and may enhance or compromise the attainment of lengthy limbs in responding to thermoregulatory stress. Positive selection for increased energetic efficiency during locomotion would also promote elongation of the lower limb generally and the leg in particular. In a highly mobile hunting and foraging society, selection for locomotor efficiency may derive through the conferral of differential reproductive success on individuals with increased stride length. However, an adequate nutritional foundation, providing essential nutrients for accelerated skeletal growth, must be readily available. Paradoxically, while the dental record at Damdama reveals high rates of enamel hypoplasia-evidence that periodic food shortages were not uncommon-catch-up growth during times of abundance clearly permitted the attainment of tall stature and long limbs characteristic of the Mesolithic inhabitants of the Ganga Plains (Lukacs and Pal 1993).

\section{CONCLUSIONS}

The findings reported here expand our knowledge of Mesolithic life-ways in the Ganga Plains of North India. Previous bioarchaeological research has documented 
low rates of dental pathology, large tooth size, tall stature, and generally good health among the inhabitants of Damdama, Sarai Nahar Rai, and Mahadaha. This study examined the relative rugosity of entheses and musculoskeletal stress markers, prevalence of osteoarthritis, long bone lengths and proportions, and variation in stature among 47 specimens from Damdama. Salient conclusions derived from this research include:

1. In size and prominence, most entheses (muscle attachment sites) display a normal range of variation, however two areas: (a) the elbow and forearm, and (b) the posterior surface of the tibia, exhibit enlarged and especially rugose entheses. Functional interpretation of these hypertrophic entheses suggest that the forearm was used in forceful overhand throwing with the right hand, and that the leg was used in walking great distances, possibly with heavy loads or in hilly terrain.

2. Evidence of osteoarthritis is rare, and suggests that potential factors that predispose onset of degenerative bone disease such as trauma and severe occupational stresses were also rare. Osteoarthritis was observed most frequently as marginal vertebral osteophytes, suggesting that activity and weight-bearing forces such as compression and torsion influenced this region of the axial skeleton. Bones of the hand and the elbow joint also displayed osteoarthritic modification, but few specimens were affected.

3. The people of Damdama, like their neighbors at Mahadaha and Sarai Nahar Rai, are tall, especially tall when compared with the stature of Mesolithic skeletal series from Western and Eastern Europe. While good health and nutrition undoubtedly contributed to their tall stature, selection for a linear body size and shape adapted to life in seasonally hot and arid environments may also have played a role. Limb proportions display distal segment elongation, frequently interpreted as one component of a thermoregulator response to hot climates.

4. Are the Mesolithic inhabitants of North India morphologically robust? The answer, both yes and no, may appear equivocal, but depends upon the frame of reference and the skeletal character under consideration. Traditional indices of robusticity suggest that like Australian aboriginals, Mesolithic skeletal series of the Ganga Plain are unusually gracile. Gracility of the appendicular skeleton may result from selective influences of heat stress and locomotor efficiency. By contrast, if musculoskeletal stress markers and entheses are the focus of attention, a high degree of muscularity is evident in particular regions of the body - the forearm and the leg-where repetitive and powerful movements related to throwing and walking predominate.

\section{ACKNOWLEDGMENTS}

We express deep appreciation to past directors of the Department of Ancient History, Culture and Archaeology, Allahabad University: Dr. V. D. Misra, Dr. S. C. Bhattacharya, and Dr. U. N. Roy, for providing access to the valuable skeletal collections under their care and for making research at Allahabad University both comfortable and productive.

Financial support for this and related research on the Mesolithic skeletons at Allahabad University was provided by the American Institute of Indian Studies (1974-1975, 1991-1992), National Geographic Society (1988, 1993, 1996), National Science Foundation (1994), and Wenner-Gren Foundation for Anthropological Research (1994-1995, International Collaborative Research Award). 
Special thanks to Sveta Chekmir, Greg Nelson, and Gwen Robbins for assistance in various phases of research on the Damdama skeletal collection, and to my wife Shirley and daughter Sarah for their sacrifices in support of the project.

\section{REFERENCES CITED}

Afanas‘ev, G., S. Cleuziou, J. R. Lukacs, and M. Tosi, eds.

1996 The Prehistory of Asia and Oceania. Forlì: ABACO Edizioni.

Allen, J. A.

1877 The influence of physical conditions in the genesis of species. Radical Review 1:108140 .

Aufderheide, A. C., C. Rodriguez-Martin, and O. Langsjoen

1998 The Cambridge Encyclopedia of Human Palcopathology. Cambridge: Cambridge University Press.

Bergmann, C.

1847 Über die Verhältnisse der Wärmeökonomie der Thiere ihurer Grösse. Goettinger Studentien. 8

BRIDGES, P.

1989 Changes in activities with the shift to agriculture in the Southeastern United States. Current Anthropology 30(3):385-394.

Chattopadhyaya, I., and U. Chattopadhyaya

1990 The spatial organization of mortuary practices in the Mesolithic Ganga Valley: Implications for territoriality, in Adaptation and Other Essays: 103-119, ed. N. C. Ghosh and S. Chakrabarti. Shantiniketan: Visva Bharati.

Chattopadhyaya, U. C.

1996 Settlement pattern and the spatial organization of subsistence and mortuary practices in the Mesolithic Ganges Valley, north-central India. World Archaeology 27(3): 461-476.

Collier, S.

1989 The influence of economic behaviour and environment upon robusticity of the postcranial skeleton: A comparison of Australian Aborigines and other populations. Archaeology Oceania $24: 17-30$.

Erlandon, J. E., And M. L. Moss

2001 Shellfish feeders, carrion eaters, and the archaeology of aquatic adaptations. American Antiquity 66(3): 413-423.

Formicola, V., and M. Giannecchini

1999 Evolutionary trends of stature in Upper Paleolithic and Mesolithic Europe. Journal of Human Evolution 36:319-333.

Gamble, L. H., P. L. Walker, and G. S. Russell

2001 An integrative approach to mortuary analysis: Social and symbolic dimensions of Chumash burial practices. American Antiquity 66(2): 185-212.

Haas, J., J. E. Buikstra, D. H. Ubelaker, and D. Aftandilian

1994 Standards for Data Collection from Human Skeletal Remains: Proceedings of a Seminar at the Field Museum of Natural History. Arkansas Archeological Survey research series; no. 44. Arkansas Archeological Survey, Fayetteville, AR.

HAWKEY, D. E.

1998 Disability, compassion, and the skeletal record: Using musculoskeletal stress markers (MSM) to construct an osteobiography from early New Mexico. International Journal of Osteoarchacology 8(5):326-340.

HaWKeY, D. E., AND C. F. MerbS

1995 Activity-induced musculoskeletal stress markers (MSM) and subsistence strategy changes among ancient Hudson Bay Eskimos. International Journal of Osteoarchacology' 5(4):324338.

Hemphill, B. E.

1999 Wear and tear: Osteoarthritis as an indicator of mobility among Great Basin huntergatherers, in Prehistoric Lifeways in the Great Basin Wetlands: 241-289, ed. B. E. Hemphill and C. S. Larsen. Salt Lake City: University of Utah Press. 
Hilison, S.

2000 Dental pathology, in Biological Anthopology of the Human Skeleton: 249-286, ed. M. A. Katzenberg and S. R. Saunders. New York: Wiley-Liss, Inc.

2001 Recording dental caries in archaeological human remains. International Journal of Osteoarchaeology 11(4) :249-289.

HoLLiday, T. W.

1999 Brachial and crural indices of European late Upper Paleolithic and Mesolithic humans. Journal of Human Evolution 36:549-566.

Jurmain, R.

1999 Stories from the Skeleton: Behavioral Reconstruction in Human Osteology. Amsterdam: Gordon and Breach.

Kajale, M. D.

1996 Plant resources and diet among the Mesolithic hunters and foragers, in The Prelistory of Asia and Oceania: 251-253, ed. G. Afanas'ev, S. Cleuziou, J. R. Lukacs, and M. Tosi, vol. 16. Forlì: ABACO Edizioni.

KENNEDY, K.A.R.

1983 Morphological variation in ulnar supinator crests and fossae as identifying markers of occupational stress. Journal of Forensic Sciences 28(4) : 871-887.

1996 Skeletal adaptations of Mesolithic hunter-foragers of North India: Mahadaha and Sarai Nahar Rai compared, in The Prehistory of Asia and Oceania: 291-300, ed. G. Afanas'ev, S. Cleuziou, J. R. Lukacs, and M. Tosi, vol. 16. Forlì: ABACO Edizioni.

2000 God-Apes and Fossil Men: Paleoanthropology in South Asia. Ann Arbor: University of Michigan Press.

Kennedy, K.A.R., N. C. Lovell, and C. B. Burrow

1986 Mesolithic Human Remains from the Gangetic Plains: Sarai Nahar Rai. Occasional Papers and Theses of the South Asia Program, No. 10. Cornell University, Ithaca.

Kennedy, K.A.R., J. R. Lukacs, R. F. Pastor, T. L. Johnston, N. C. Lovell, J. N. Pal, and C. B. Burrow

1992 Human Skeletal Remains from Mahadaha: A Gangetic Mesolithic Site. Occasional Papers and Theses of the South Asia Program, No. 11. Cornell University, Ithaca.

Lai, P., and N. C. Lovell

1992 Skeletal markers of occupational stress in the fur trade: A case study from a Hudson's Bay Company fur trade post. International Journal of Osteoarchaeology 2(3):221-234.

LARSEN, C. S.

1997 Bioarchaeology. Cambridge: Cambridge University Press.

LOVell, N. C.

1994 Spinal arthritis and physical stress at Bronze Age Harappa. American Journal of Physical Anthropology 93(2): 149-164.

1997 Trauma analysis in paleopathology. Yearbook of Physical Antluropology 34:139-170.

2000 Paleopathological description and diagnosis, in Biological Anthropology of the Human Skeleton: 217-246, ed. M. A. Katzenberg and S. R. Saunders. New York: Wiley-Liss, Inc.

LUKaCS, J. R.

1977 Anthropological Aspects of Dental Variation in North India: A Morphometric Analysis. Unpublished Ph.D. diss. Cornell University, Ithaca.

1996 Sex differences in dental caries rates with the origin of agriculture in South Asia. Current Anthropology 37(1):147-153.

2002 Hunting and gathering strategies in prehistoric India: A biocultural perspective on trade and subsistence, in Forager Traders in South and Southeast Asia: 41-61, ed. K. Morrisson and L. Junker. Cambridge: Cambridge University Press.

Lukacs, J. R., and B. E. Hemphill

1991 The dental anthropology of prehistoric Baluchistan: A morphometric approach to the peopling of South Asia. Advances in Dental Anthropology: 77-119, ed. M. A. Kelley and C. S. Larsen. New York: Wiley-Liss, Inc.

LuKacs, J. R., and V. D. Misra

1997 The people of Lekhahia: A biocultural portrait of late Mesolithic foragers of North India, in South Asian Arclacology 1995: 873-889, ed. R. Allchin and B. Allchin. New Delhi: Oxford-IBH and Science Publ. 
Lukacs, J. R., AND V. D. Misra

2002 Human skeletons at Lekhahia, in Mesolithic India, eds. J. R. Lukacs and V. D. Misra. Allahabad: Department of Ancient History, Culture and Archaeology. 261-288.

Lukacs, J. R., AND J. N. PAL

1992 Dental anthropology of Mesolithic hunter-gatherers: A preliminary report on the Mahadaha and Sarai Nahar Rai dentition. Man and Environment 19(2):45-55.

1993 Mesolithic subsistence in North India: Inferences from dental pathology and odontometry. Current Anthropology 34(5): 745-765.

2003 Paleopathology and subsistence transition theory: New evidence from Mesolithic Damdama, in R. K. Vama Felicitation Volumie, ed. V. D. Misra, J. N. Pandey, and J. N. Pal. Allahabad. In press.

Lukacs, J. R., J. N. PAl, And V. D. Misra

1996 Chronology and diet in Mesolithic North India: A preliminary report of new AMS ${ }^{1+} \mathrm{C}$ dates, $\delta^{13} \mathrm{C}$ isotope values, and their significance, in The Prehistory of Asia and Occania: 301-311, ed. G. Afanas'ev, S. Cleuziou, J. R. Lukacs, and M. Tosi, vol. 16. Forlì: $\mathrm{ABACO}$ Edizioni.

LuKaCS, J. R., AND S. R. WALImbe

1998 Physiological stress in prehistoric India: New data on localized hypoplasia of primary canines linked to climate and subsistence change. Journal of Archacological Science $25: 571-585$.

Lukacs, J. R., S. R. Walimbe, and G. C. Nelson

2001 Enamel hypoplasia and childhood stress in prehistory: New data from India and southwest Asia. Journal of Archaeological Science 28:1159-1169.

Misra, V. D.

1996 History and context of Mesolithic research at Allahabad University, Allahabad, India, in The Prehistory of Asia and Oceania: 245-250, ed. G. Afanas'ev, S. Cleuziou, J. R. Lukacs, and M. Tosi, vol. 16. Forli: ABACO Edizioni.

Misia, V. N.

1996 Mesolithic India: History and current status of research, in The Prehistory of Asia and Oceania: 321-328, ed. G. Afanas'ev, S. Cleuziou, J. R. Lukacs, and M. Tosi, vol. 16. Forlì: ABACO Edizioni.

MOLLESON, T.

1989 Seed preparation in the Mesolithic: The osteological evidence. Antiquity 63:356-362.

MOLlesOn, T., AND J. BlONDIAUX

1994 Riders' bones from Kish, Iraq. Cambridge Archacological Journal 4(2):312-316.

Molleson, T., AND 1). Hodgson

1993 Cart driver from Ur. ArchacoZoologia 6(1):93-106.

Ortner, D., and W. Putschar

1981 Identification of Pathological Conditions in Human Skeletal Remains. Contributions to Anthropology, No. 28. Smithsonian Institution, Washington, D.C.

PAL, J. N.

1985 Some new light on the Mesolithic burial practices of the Ganga Valley: Evidence from Mahadaha, Pratapgarh, Uttar Pradesh. Man and Environment 9:28-37.

1988 Mesolithic double burials from recent excavations at Dandama. Man and Environment $12: 115-122$

1992 Mesolithic human burials from the Gangetic Plain, North India. Man and Emvironment $17(2): 35-44$.

1996 Lithic use wear analysis and subsistence activities among the Mesolithic people of North India, in The Prehistory of Asia and Oceania: 267-277, ed. G. Afanas'ev, S. Cleuziou, J. R. Lukacs, and M. Tosi, vol. 16. Forli: ABACO Edizioni.

PANDEY, J. N.

1996 Burial practices and funerary practices of Mesolithic India, in The Prehistory of Asia and Occania: 279-29(), ed. G. Afanas'ev, S. Cleuziou, J. R. Lukacs, and M. Tosi, vol. 16. Forli: ABACO Edizioni.

PeARSON, O. M

200() Activity, climate, and postcranial robusticity: Implications for modern human origins and scenarios of adaptive change. Current Antluropology' 41(4):569-605. 
Petraglia, M., P. Laporta, and K. Paddayya

1999 The first Acheulian quarry in India: Stone tool manufacture, biface morphology, and behaviors. Journal of Anthropological Research $55: 39-70$.

Possehl, G. L., and P. C. Rissman

1992 The chronology of prehistoric India: from earliest times to the Iron Age, in Chronologics in Old World Archaeology, vol. 1:465-490, ed. R. W. Ehrich. Chicago: University of Chicago Press.

PotTs, R.

1988 Early' Hominid Activities at Olduvai. New York: Aldine de Gruyter.

ROBB, J. E.

1998 The interpretation of skeletal muscle sites: A statistical approach. Interinational Joumal of Osteoarchaeology 8(5):363-377.

Robb, J. E., R. Bigazzi, L. Lazzarini, C. Scarsini, and F. Sonego

2001 Social status and biological status: A comparison of grave goods and skeletal indicators from Pontecagnano. American Journal of Physical Anthropology 115(3):213-222.

Robins, G.

2000 Dental histology and age estimation in prehistoric skeletons from South Asia. Masters thesis. Department of Anthropology, University of Oregon, Eugene.

Roberts, C., AND K. ManChester

1995 The Archacology of Disease. Ithaca, NY: Cornell University Press.

RuFF, C. B.

1999 Skeletal structure and behavioral patterns of prehistoric Great Basin populations, in Prehistoric Lifeways in the Great Basin Wetlands: Bioarchaeological Reconstruction and Interpretation: 290-320, ed. B. E. Hemphill and C. S. Larsen. Salt Lake City: University of Utah Press.

2000 Biomechanical analyses of archaeological human skeletons, in Biological Anthropology of the Human Skeleton: 71-102, ed. A. M. Katzenberg and S. R. Saunders. New York: WileyLiss, Inc.

Sharma, D. P. and M. Sharma

1987 A reappraisal of the chronology of Mesolithic and Neolithic cultures of the Vindhyas and middle Ganga Valley, in Archacology and History: Essays in Memory of Shri A Ghosh: 57-66, ed. B. M. Pandey and B. D. Chattopadhyaya. Delhi: Agam Kala Prakashan.

SHARma, G. R.

1973 Mesolithic lake cultures of the Ganga Valley, India. Procedings Prehistoric Socicty $39: 129-146$

Sharma, G. R., V. D. Mishra, D. Mandal, B. B. Mishra, and J. N. Pal, eds.

1980 Begimnings of Agriculture. Allahabad: Abinash Prakashan.

STOCK, J., AND S. PFeiffer

2001 Linking structural variability in long bone diaphyses to habitual behaviors: Foragers from the southern African later Stone Age and the Andaman Islands. American Jourmal of Plysical Anthropology' 115(4):337-348.

STOREY, R.

1992 Life and Death in the Ancient City of Teotihuacan: A Modern Paleodemographic Synthesis. Tuscaloosa: University of Alabama Press.

Thomas, P. K., P. P. Joglekar, V. D. Mishra, J. N. Pandey, and J. N. Pal

1996 Faunal evidence for the Mesolithic food economy of the Gangetic Plain with special reference to Damdama, in The Prehistory of Asia and Oceania: 255-266, ed. G. Afanas'ev, S. Cleuziou, J. R. Lukacs, and M. Tosi, vol. 16. Forli: ABACO Edizioni.

Trinkaus, E.

1981 Neandertal limb proportions and cold adaptation, in Aspects of Human Evolution: 187-224, ed. C. B. Stringer. London: Taylor and Francis.

TROTTER, M.

1970 Estimation of stature from intact long bones, in Personal Identification in Mass Disasters: 71-83, ed. T. D. Stewart. Washington, D.C.: National Museum of Natural History.

Trotter, M., and G. C. Gleser

1958 A re-evaluation of stature based on measurements taken during life and of bones after death. American Journal of Pliysical Anthropology 16: 79-123. 
UBELAKER, D. H.

1989 Human skeletal remains: Excanation, analysis, interpretation. Manuals on Archeology 2. Washington, D.C.: Taraxacum.

VARMA, R. K.

1981- The Mesolithic cultures of India. Puratattva 13-14:27-36.

1983

1996 Subsistence economy of the Mesolithic folk as reflected in the rock-paintings of the Vindhya region, in The Prehistory of Asia and Oceania: 329-339, ed. G. Afanas'ev, S. Cleuziou, J. R. Lukacs, and M. Tosi, vol. 16. Forlì: ABACO Edizioni.

Varma, R. K., V. D. Misra, J. N. Pandey, and J. N. Pal

1985 A preliminary report on the excavations at Damdama (1982-1984). Man and Environment $9: 45-65$.

WALKER, A., AND R. LEAKEy, EDS.

1993 The Nariokotome Homo erectus Skeleton. Cambridge: Harvard University Press.

WAlKer, P. L., AND B. HewletT

1990 Dental health, diet, and social status among Central African foragers and farmers. American Anthropologist 92(2):383-398.

Walker, P. L., L. Sugiyama, and R. Chacon

1998 Diet, dental health and culture change among recently contacted South American Indian hunter-horticulturalists, in Human Dental Development, Morphology, and Pathology: A Tribute to Albert A. Dahlberg: 355-386, ed. J. R. Lukacs. University of Oregon Anthropology Paper No. 54, Eugene.

WhiTE, T. D.

1992 Prehistoric Camnibalism at Mancos 5MTUMR-2346. Princeton: Princeton University Press.

\section{ABSTRACT}

Rethinking new perspectives in South Asian archaeology necessitates wider appreciation for insights derived from the bioarchaeological analysis of prehistoric human skeletons. Since the 1970s, Mesolithic sites near Allahabad (Uttar Pradesh) have yielded abundant well-preserved human skeletons permitting a bioarchaeological approach to past life-ways. Prior research on human remains from Sarai Nahar Rai and Mahadaha is supplemented by this analysis of human skeletal variation in 47 specimens from Damdama. This report examines skeletal variation in muscle attachment sites (entheses) and musculoskeletal stress markers, prevalence of osteoarthritis, long bone dimensions and proportions, and estimates of stature for the human skeletons from Damdama. The objective of this study is to better understand habitual activity patterns, variation in stature, and adaptation to climate among Mesolithic foragers of North India. Standardized methods of paleopathology, osteometry, and stature estimation were used. While most entheses displayed a "normal" range of development, those associated with bipedal locomotion and overhand throwing were especially well developed. Extreme hypertrophy of the soleal line indicates repetitious and forceful plantar flexion as in walking long distances, up hills, or with heavy loads. Hypertrophy of the supinator crest suggests forceful overhand throwing as in launching spears or projectiles. Osteoarthritis is unusually low in frequency, though spinal osteophytes and arthritis of the hand and elbow were observed. Stature is tall at Damdama, a trait shared with inhabitants of Sarai Nahar Rai and Mahadaha. Collectively, North Indian Mesolithic groups are significantly taller than Eastern or Western European Mesolithic samples. Long lower limbs may be an adaptation to locomotor efficiency, but may also reflect adaptation to high seasonal temperatures. Indices of distal to proximal limb segments for both upper and lower extremities conform to physiological principles of thermoregulation and suggest biological adaptation to a hot arid enviromment. KEYwOrDs: bioarchaeology, entheses, osteoarthritis, stature, limb proportions, climate adaptation, activity pattern, Mesolithic. 